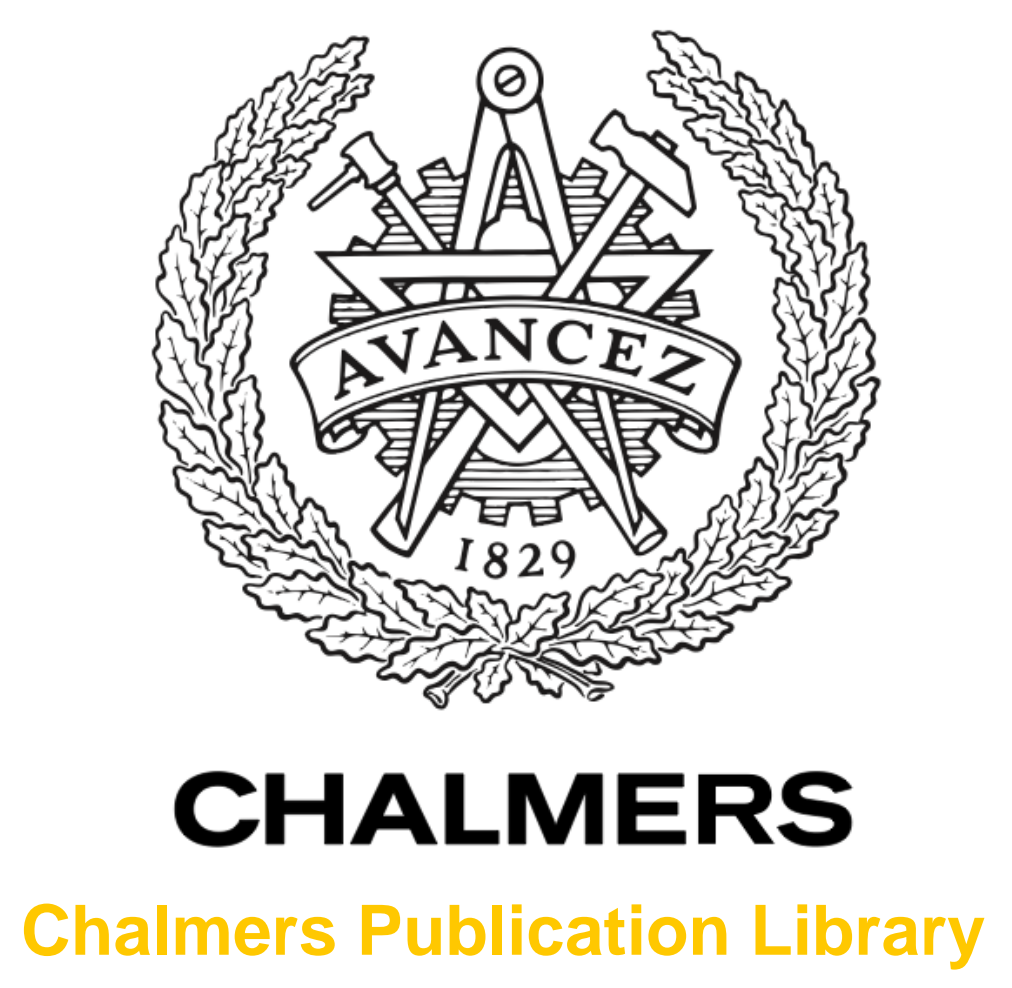

\title{
Optimizing Wind Power Hosting Capacity of Distribution Systems Using Cost Benefit Analysis
}

This document has been downloaded from Chalmers Publication Library $(\mathrm{CPL})$. It is the author's version of a work that was accepted for publication in:

leee Transactions on Power Delivery (ISSN: 0885-8977)

Citation for the published paper:

Nursebo, S. ; Chen, P. ; Carlson, O. et al. (2014) "Optimizing Wind Power Hosting Capacity of Distribution Systems Using Cost Benefit Analysis". Ieee Transactions on Power Delivery, vol. 29(3), pp. 1436-1445.

http://dx.doi.org/10.1109/tpwrd.2014.2303204

Downloaded from: http://publications.lib.chalmers.se/publication/200386

Notice: Changes introduced as a result of publishing processes such as copy-editing and formatting may not be reflected in this document. For a definitive version of this work, please refer to the published source. Please note that access to the published version might require a subscription. 


\title{
Optimizing Wind Power Hosting Capacity of Distribution System Using Cost Benefit Analysis
}

\author{
S. Nursebo, P. Chen, member, IEEE, O. Carlson, L. Bertling Tjernberg, Senior Member, IEEE
}

\begin{abstract}
The penetration of wind power into the electricity grid is growing significantly. A significant portion of this wind power is being installed in distribution systems, of which most are passively operated. Under this operating practice, wind power can only be admitted based on minimum load and maximum generation consideration. This severely limits the wind power hosting capacity of the system. Hence, the use of active management strategies (AMSs) has been proposed to increase the hosting capacity of distribution systems. This paper incorporates AMSs into two optimization models whose objectives are to maximize the net benefit of distribution system operator (DSO) and wind farm owner (WFO), respectively. The AMSs considered are wind energy curtailment (WEC), coordinated on-load tap changer(OLTC) voltage control and reactive power compensation (RPC). The models development is based on a typical medium voltage distribution system in Sweden although it can easily be adapted to other cases. The application of the model to a distribution system in Sweden shows an increase in hosting capacity of the distribution system by $\mathbf{7 8 \%}$ with mere $\mathbf{2 . 6 \%}$ curtailed energy. That is, the hosting capacity of the distribution system has almost been doubled by using AMSs.
\end{abstract}

Index Terms-Wind power generation, Cost benefit analysis, active management strategy, distribution system

\section{NOMENCLATURE}

\section{Sets \& Indices}

$i \quad \in I$

$I \quad$ a set containing all buses in the network

$j \in J$

$J \quad$ the set of all buses excluding the buses connected to the tap side of a transformer

$k \in K$

$K \quad$ the set of all buses excluding the buses connected to the non tap side of a transformer

$t \quad$ time index

$u \quad \in I$

\section{Constants}

$b_{k, j} \quad$ series susceptance between bus $k$ and bus $j$ [p.u.]

$b_{k, j}^{\mathrm{c}} \quad$ shunt susceptance between bus $k$ and bus $j$ [p.u.]

$C^{\mathrm{am}} \quad$ the present value of the implementation cost of AMSs

$C^{\mathrm{c}} \quad$ capital cost of wind power [€/MW]

$C^{\mathrm{e}} \quad$ cost of electricity based on spot market [€/MWh]

$C^{\mathrm{gc}} \quad$ cost of green certificate [€/MWh]

This work was financed by Chalmers Energy Initiative.

S. Nursebo Salih is with Chalmers University of Technology, Sweden (email: Shemsedin.nursebo@chalmers.se).

P. Chen is with Chalmers University of Technology, Sweden (email: peiyuan@chalmers.se).

O. Carlson is with Chalmers University of Technology, Sweden (email: Ola.carlson@chalmers.se).

L. Bertling is with Chalmers University of Technology, Sweden (email: lina.bertling@ieee.org).
$C^{\mathrm{v}} \quad$ variable costs of wind power [€/MWh]

$f^{\mathrm{mp}} \quad$ the average monthly peak power from the wind turbines [p.u.]

$f^{\text {npw }} \quad$ net present worth factor, see equation (21)

$f_{i}^{\text {cf }} \quad$ capacity factor in numbers of hours of full power production in a year

$g_{k, j} \quad$ series conductance between bus $k$ and bus $j$ [p.u.]

$h^{\mathrm{yr}} \quad$ number of hours per year[€/MWh]

$I_{k, j}^{\text {rat }} \quad$ current rating of a link between bus $k$ and $j$

$n^{\text {mon }} \quad$ number of months per year

$P_{i, t}^{\max } \quad$ maximum value of active power production at bus $i$ at time $t$ [p.u.]

$P_{i, t}^{\min } \quad$ minimum value of active power production at bus $i$ at time $t$ [p.u.]

$P_{i, t}^{\mathrm{D}} \quad$ active power consumed at bus $i$ and time $t$ [p.u.]

$P_{i, t}^{\mathrm{W}} \quad$ available wind power at time $\mathrm{t}$ and at bus $\mathrm{i}$ [p.u.]

$Q_{i, t}^{\max }$ maximum available values of reactive power at bus $i$ and time $t$ [p.u.]

$Q_{i, t}^{\min } \quad$ minimum available values of reactive power at bus $i$ and time $t$ [p.u.]

$Q_{i, t}^{\mathrm{D}} \quad$ reactive power consumed at bus $i$ and time $t$ [p.u.]

$r$ discount rate of the investment

$S_{j, k}^{\text {rat }} \quad$ the MVA rating of the transformer

$Y_{i, u} \quad$ magnitude of the $(i, u)^{t h}$ element of the bus admittance matrix [p.u.]

$y_{k, j} \quad$ series admittance between bus $k$ and bus $j$ [p.u.]

$\mathrm{Tp} \quad$ total period of the investment in years

$\varphi_{k, j} \quad$ angle of the series admittance between bus $k$ and bus $j$ [rad]

$\chi$ the net present value of the cost of the alternative investment

$\gamma \quad$ the net present worth of a MWh of electricity from wind power[€/MWh]

$\theta_{i, u} \quad$ angle of the $(i, u)^{t h}$ element of the same admittance matrix [rad]

$\rho^{\mathrm{df}} \quad$ distribution fee [€/MWh]

$\rho^{\text {pf }} \quad$ peak power fee $[€ / M W]$

$\rho^{\text {sf }} \quad$ subscription fee [€]

$\rho^{\text {tb }} \quad$ transmission benefit [€/MWh]

Variables

$n_{i} \quad$ the capacity of wind power installed at bus $i$ in MW

$n_{k, j, t} \quad$ tap ratio of the transformer between bus $k$ and bus $j$ at time $t$ [p.u.]

$P_{i, t} \quad$ active power produced at bus $i$ and time $t$ [p.u.]

$P_{i, t}^{\text {cur }} \quad$ curtailed wind energy at bus $\mathrm{i}$ and time $\mathrm{t}$ [MWh] active power flow from bus $k$ to bus $j$ at time $t$ [p.u.] reactive power produced at bus $i$ and time $t$ [p.u.] 
$Q_{k, j, t}^{\mathrm{F}} \quad$ reactive power flow from bus $k$ to bus $j$ at time $t$ [p.u.]

$V_{i, t} \quad$ voltage magnitude at node $i$ and time $t$ [p.u.]

$\Delta P^{\text {loss }} \quad$ change in the network losses $P^{\text {loss }}$ [p.u.]

$\delta_{i, t} \quad$ voltage angle at node $i$ and time $t$ [rad]

\section{INTRODUCTION}

$\mathbf{T}$ HE global installed capacity of wind power has shown a significant growth, from just $24 \mathrm{GW}$ in 2001 to 283 $\mathrm{GW}$ in 2012 [1]. This trend is expected to continue for some years to come [2]. Hence a significant amount of wind power needs to be connected to the electric power system. Usually larger wind farms are connected to transmission systems while smaller wind farms are preferably connected to distribution systems. Such preference arises from comparatively lower connection costs associated with installing wind power in lower voltage networks [3].

However, integration of wind power in a distribution system can pose a number of power quality and reliability issues to the network. Thus, distribution system operators (DSOs) use the worst case analysis when determining the wind power hosting capacity in their system. This analysis is usually based on carrying out load flow analysis using the minimum load condition in the system and the maximum expected wind power output. Various methodologies [4]-[8] have been proposed in the literature to determine the optimal sizing and siting of distributed generators based on this worst case analysis.

The approach based on worst case analysis ensures a system against potential power quality and security concerns. However, when it comes to intermittent generations, like wind power, maximum generation and minimum load rarely coincide in practice. Hence, this approach unnecessarily hinders the penetration of wind power into the electricity grid. It also deprives DSOs from the potential benefit they could gain from renewable generation. As a result, active management strategies (AMSs) have been proposed to increase the hosting capacity of distribution systems [3], [9]-[15]. The AMSs discussed in literature include coordinated on load tap changer voltage control [3], [9]-[13], [15], reactive power compensation (RPC) [3], [9]-[12], [14], [15], and wind energy curtailment (WEC) [3], [9]-[15].

However, there is still a limit to the amount of wind power that can be installed using AMSs. For example, the hosting capacity of the network can be increased by curtailing part of the wind power during network overload or overvoltage. But WEC causes loss in revenue for the WFO and cannot be used indefinitely. Similarly, RPC can be used to increase the hosting capacity of a network by avoiding overvoltage which would otherwise happen due to wind power. However, if used excessively, RPC may lead to unacceptable power losses in the network. Thus, there is a limit on the amount of wind power that can be installed using AMSs. In literature reviewed, for example, in the case of WEC, this is done either by limiting the amount of curtailed energy [9], [13]-[15] or by constraining the capacity of wind power [3], [10]-[12]. This approach, however, does not ensure optimal use of the AMSs as the limit of energy curtailed set at each case is chosen arbitrarily and not based on the cost benefit analysis.
In this paper, a model based on cost benefit analysis is proposed to determine the optimal use of AMSs thereby providing the optimal hosting capacity of distribution systems. The model is also used to compare the profitability of these AMSs with grid reinforcement.

Section II discusses the costs encountered and benefits gained by wind farm owner (WFO) and DSO in connection with wind power. The optimization model is developed in Section III. Section IV provides the results of a case study. Finally, Section V provides the conclusion of the paper.

\section{Costs \& Benefits of Wind Power}

This section provides the discussion of the main costs and benefits of both the DSO and the WFO.

\section{A. Costs \& benefits of a DSO}

1) Costs of a DSO: The DSO may encounter a significant connection cost if there is a need to reinforce the network [16]. Otherwise the connection costs up to the point of common coupling are endured by WFO. Since this study focuses on increasing the hosting capacity using the existing system, no connection cost is assumed on the DSO. Other sources of cost for the DSO due to the connection of wind power are:

- Increase in network losses due to reverse power flow

- Curtailed wind energy, depending on the agreement between the DSO and WFO

- Infrastructure for implementing AMSs

2) Benefits of a DSO: Network investment deferral can be seen as the major benefit of distributed generations in general. However, due to uncontrollability of the energy input (i.e wind speed) at the wind turbines and low correlation between stochastic load and wind power data, wind farms can only make minor contribution to network investment deferral.

Moreover, in countries like Sweden and UK, the WFO pays the DSO network fee for using the network [8]. This network fee usually breaks down into a combination of any of the following ones as determined by different regulatory frameworks [17]-[19]:

- Fixed charge per month or per year

- A fee based on $\mathrm{kW}$ installed or maximum injected per month or per year

- A fee based on kWh energy transmitted by the network

- A fee based on kVArh reactive power consumed and transmitted

\section{B. Costs \& benefits of a WFO}

1) Costs of a WFO: The overall expenses of the WFO are affected by numerous parameters such as the capital and variable costs of the wind turbine, the discount rates, and the economic lifetime of the wind turbine [20].

a) Capital costs: The capital cost includes the costs of the wind turbines, foundation, road construction, grid connection and other project development and planning costs. According to the report by European wind energy association (EWEA) [2], the capital cost in Europe differs between 1 million $€ / \mathrm{MW}$ and 1.35 million $€ / \mathrm{MW}$ and the average 
turbine installed in Europe costs 1.23 million $€ / M W$. Future forecasts by both European commission and European wind energy association show that the capital cost will be lower than what it is today [2]. Moreover, the lifetime of the wind turbine is around 20 for onshore wind turbines and 25 years for offshore ones [2].

b) Variable costs: Variable costs include expenses pertaining to [20]

- operation and maintenance (O\&M) cost, which includes regular maintenances, repairs and spare parts

- Land rental

- Insurances and taxes

- Administration, including audits, management activities, forecasting services and remote control measures.

The current estimate of these variable costs obtained from EWEA is between 12 to $15 € / \mathrm{MWh}$ [2].

2) Benefits of a WFO: In most countries renewable energy, hence wind power, is supported through regulating either the price or quantity of electricity from these sources [2]. In Sweden, green certificate is used to support energy from renewable sources. The average green certificate price in Sweden for 2011 was $27.92 € / M W h$ [21] and the average electricity price at spot market was $47.85 € / \mathrm{MWh}$ [22]. Hence the average revenue gained in 2011 by producing one MWh of electricity from wind power is $75.77 €$.

\section{The Optimization Model}

This section develops a mathematical model that can be used to determine the optimal wind power hosting capacity of a distribution system. Separate objective functions are formulated for each actor (i.e. DSO and WFO) and optimized independently. However, the value of the other objective function is calculated to compare the result between the cases. Both objective function are subject to the same equality and inequality constraints as provided below.

\section{A. The Objective function}

1) The Objective function of the DSO: Here it is assumed that the DSO agrees to pay the WFO for the curtailed energy. Hence, the objective, as formulated in (1), maximizes the net benefit of the DSO while covering the cost of curtailed energy and increase in network losses.

$$
\max _{n_{i}, P_{i, t}^{\mathrm{cur}}} O=\sum_{i} a_{i} n_{i}-\sum_{i} \sum_{t} b_{i} P_{i, t}^{\mathrm{cur}}-c \Delta P^{\mathrm{loss}}+d
$$

where

$$
P^{\text {loss }}=\frac{1}{T} \sum_{t}^{T} \sum_{k} \sum_{j<k} g_{k, j}\left(\begin{array}{l}
\left(\frac{V_{k, t}}{n_{k, j, t}}\right)^{2}+V_{j, t}^{2}-\frac{2 \cdot V_{k, t} \cdot V_{j, t}}{n_{k, j, t}} \\
\times \cos \left(\delta_{j, t}-\delta_{k, t}\right)
\end{array}\right)
$$

The roles of the different terms in the objective function are described as follows.

- The first term accounts for the revenue from the network fee. The cost saving due to network investment deferral can also be included according to the calculation in [23].

- The second term accounts for the cost of curtailed energy.
- The third term represents the cost of increased network losses.

- The last term represents any constant revenue or expense, e.g. subscription fee, investment cost of the infrastructure for implementing AMSs.

The coefficients of each term should be calculated as the present worth of the associated cost or benefit during the lifetime of the wind turbine.

2) The objective function of the WFO: Here it is assumed that the WFO bears the cost of curtailed energy. Hence the objective function which maximizes the net benefit of the WFO is formulated as:

$$
\max _{n_{i}, P_{i, t}^{\text {cur }}} O=\sum_{i} \alpha_{i} n_{i}-\sum_{i} \sum_{t} \beta_{i} P_{i, t}^{\mathrm{cur}}+\kappa
$$

In this objective function:

- The first term accounts for revenues (including electricity and green certificate sell) and costs (investment cost, O\&M costs) per kW of installed capacity.

- Loss in revenue due to curtailed energy is accounted for by the second term.

- The last term represents any constant revenues or expenses.

Similar to the case of DSO, the coefficients in (3) should be calculated as the present worth of the associated cost or benefit during the lifetime of the wind turbine.

\section{B. The constraints}

The objective functions proposed in the previous subsection are subject to different equality and inequality constraints. These constraints are described below.

1) Equality constraints: The equality constraints are the load flow equations [24].

$$
\begin{aligned}
& P_{i, t}-P_{i, t}^{D}=\sum_{j} Y_{i, u} V_{i, t} V_{u, t} \cos \left(\theta_{i, u}+\delta_{u, t}-\delta_{i, t}\right) \\
& Q_{i, t}-Q_{i, t}^{D}=-\sum_{j} Y_{i, u} V_{i, t} V_{u, t} \sin \left(\theta_{i, u}+\delta_{u, t}-\delta_{i, t}\right)
\end{aligned}
$$

Where, for buses to which wind power is connected, $P_{i, t}$ can be replaced by:

$$
P_{i, t}=n_{i} P_{i, t}^{\mathrm{W}}-P_{i, t}^{\mathrm{cur}}
$$

However whenever the hosting capacity is limited due to voltage rise problem, the limits on the tap ratio may be violated. Hence under such condition, there is a need to constrain the tap ratio within its limit. One way of doing this can be modifying the load flow equations to include the tap ratio as given in [25]. The modified load flow equations proposed in [25] are given in (6)-(9) below.

For a bus connected to the tap side of a transformer:

$$
\begin{aligned}
& P_{k, t}-P_{k, t}^{D}=\sum_{j} P_{k, j, t}^{\mathrm{F}} \\
& Q_{k, t}-Q_{k, t}^{D}=\sum_{j} Q_{k, j, t}^{\mathrm{F}}
\end{aligned}
$$

For any other bus:

$$
\begin{aligned}
& P_{j, t}-P_{j, t}^{\mathrm{D}}=\sum_{k} P_{j, k, t}^{\mathrm{F}} \\
& Q_{j, t}-Q_{j, t}^{\mathrm{D}}=\sum_{k} Q_{j, k, t}^{\mathrm{F}}
\end{aligned}
$$


where

$$
\begin{aligned}
P_{k, j, t}^{\mathrm{F}} & =\left(\frac{V_{k, t}}{n_{k, j, t}}\right)^{2} g_{k, j}-\frac{V_{k, t} V_{j, t}}{n_{k, j, t}} y_{k, j} \cos \left(\delta_{j, t}-\delta_{k, t}+\varphi_{k, j}\right) \\
Q_{k, j, t}^{\mathrm{F}} & =-V_{k, t}^{2}\left(\frac{b_{k, j}}{n_{k, j, t}^{2}}+\frac{b_{k, j}^{\mathrm{c}}}{2}\right)+\frac{V_{k, t} V_{i, t}}{n_{k, j, t}} y_{k, j} \sin \left(\delta_{j, t}-\delta_{k, t}+\varphi_{k, j}\right)
\end{aligned}
$$

and

$$
\begin{aligned}
& P_{j, k, t}^{\mathrm{F}}=V_{j, t}^{2} g_{j, k}-\frac{V_{j, t} V_{k, t}}{n_{k, j, t}} y_{j, k} \cos \left(\delta_{k, t}-\delta_{j, t}+\varphi_{k, j}\right) \\
& Q_{j, k, t}^{\mathrm{F}}=-V_{j, t}^{2}\left(b_{j, k}+\frac{b_{j, k}^{\mathrm{c}}}{2}\right)+\frac{V_{j, t} V_{k, t}}{n_{k, j, t}} y_{j, k} \sin \left(\delta_{k, t}-\delta_{j, t}+\varphi_{k, j}\right)
\end{aligned}
$$

But, whenever there is no concern of violating the tap ration limits it is better to use (4) as it can save considerable simulation time.

2) Inequality constraints: The inequality constraints include the limit on the thermal capacity (current limit) of network components. This includes the limit on the ampacity of cables, as given by $(10)^{1}$, and the power rating of the substation transformer, as given by (11),

$$
\begin{aligned}
y_{k, j}^{2}\left(V_{k, t}^{2}+V_{j, t}^{2}-2 V_{k, t} V_{j, t} \cos \left(\delta_{j, t}-\delta_{k, t}\right)\right) & \leq\left(I_{k, j}^{\mathrm{rat}}\right)^{2} \forall k>j \\
y_{k, j}^{2} V_{j, t}^{2}\left(\left(\frac{V_{k, t}}{n_{k, j, t}}\right)^{2}+V_{j, t}^{2}-\frac{2 \cdot V_{k, t} \cdot V_{j, t}}{n_{k, j, t}}\right. & \left.\times \cos \left(\delta_{j, t}-\delta_{k, t}\right)\right) \\
& \leq\left(S_{j, k}^{\mathrm{rat}}\right)^{2} \quad \forall k>j
\end{aligned}
$$

the limit on the available range of tap ratio,

$$
n_{k, j}^{\min } \leq n_{k, j, t} \leq n_{k, j}^{\max }
$$

the voltage limits on each bus,

$$
V_{i}^{\min } \leq V_{i, t} \leq V_{i}^{\max }
$$

the limit on the AMS costs, i.e. the cost of curtailed energy and the implementation cost of AMS $C^{\mathrm{am}}$, mainly compared to the alternative investment such as reinforcement,

$$
\gamma \sum_{i} \sum_{t} P_{i, t}^{\mathrm{cur}}+C^{\mathrm{am}} \leq \chi
$$

and the limit on available active and reactive power at each bus.

$$
\begin{aligned}
& P_{i, t}^{\min } \leq P_{i, t} \leq P_{i, t}^{\max } \\
& Q_{i, t}^{\min } \leq Q_{i, t} \leq Q_{i, t}^{\max }
\end{aligned}
$$

$P_{i, t}$ and $Q_{i, t}$ do not need to be bounded at the slack bus. Hence, at this bus, $P_{i, t}^{\min }$ and $Q_{i, t}^{\min }$ can be assigned $-\infty$ while $P_{i, t}^{\max }$ and $Q_{i, t}^{\max }$ can be set to $+\infty$. For buses with wind power where $P_{i, t}$ is replaced as in (5), the constraint on $P_{i, t}^{\text {cur }}$ can be given by (16)

$$
0 \leq P_{i, t}^{\mathrm{cur}} \leq n_{i} P_{i, t}^{\mathrm{W}}
$$

and $Q_{i, t}^{\min }, Q_{i, t}^{\max }$ are given by (17).

$$
\begin{aligned}
Q_{i, t}^{\min } & =-n_{i, t} P_{i, t}^{\mathrm{W}} \frac{\sqrt{1-\eta^{2}}}{\eta} \\
Q_{i, t}^{\max } & =n_{i, t} P_{i, t}^{\mathrm{W}} \frac{\sqrt{1-\eta^{2}}}{\eta}
\end{aligned}
$$

${ }^{1}$ In $\pi$ - model of a line the current that passes through the resistive element and causes thermal overheating can be calculated using $I_{k, j}=$ $y_{k, j} e^{i \varphi_{k, j}}\left(V_{k, t} e^{i \delta_{k}}-V_{j, t} e^{i \delta_{j}}\right)$ and this gives (10). Similar analysis on the pi model of a transformer gives (11). where $\eta$ is the minimum operating power factor level of the wind turbine. For the rest of the buses all limits, i.e. $P_{i, t}^{\min }, P_{i, t}^{\max }$, $Q_{i, t}^{\min }$, and $Q_{i, t}^{\max }$ should be zero. Reactive power production from the wind turbines can be used to reduce the system losses hence increase the net benefit of the DSO.

From the formulation above it can be observed that the model is a non linear programming (NLP) problem with multiperiod OPF. In this paper, the problem is solved using GAMS with an interior-point based solver (IPOPT) [26].

\section{CASE STUDY}

\section{A. Network and data description}

1) Network description: The case study is based on a rural $11 \mathrm{kV}$ distribution system operated by Falbygdens Energi located in Falköping area in Sweden. The network is fed by a $40 \mathrm{kV}$ grid through a $45 \pm 8 \times 1.67 \% / 11.5 \mathrm{kV}, 10 \mathrm{MVA}$ transformer. The tap changer of the transformer regulates the low voltage side of the transformer at $0.97 \pm 0.012$ p.u. The voltage in the distribution system should be within $\pm 5 \%$ of the nominal value. There are 13 wind turbines, with overall installed capacity of $12.225 \mathrm{MW}$, already connected to the distribution system. A new wind farm is to be connected directly to the substation with an independent cable (see Fig 1). The distance of the wind farm from the substation is $5 \mathrm{~km}$.

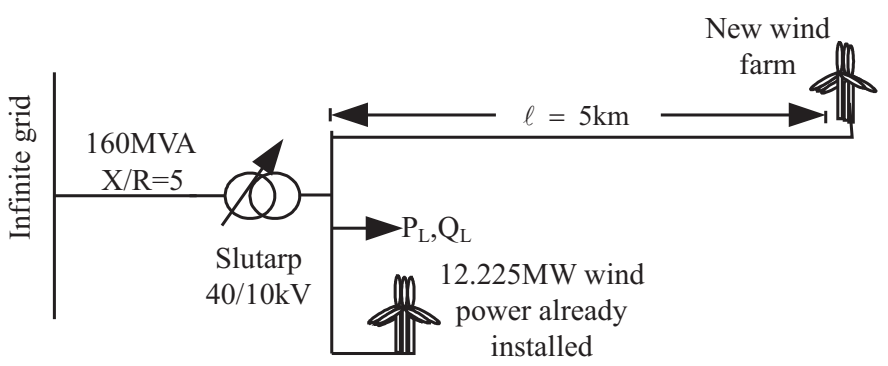

Fig. 1: Simplified network of Falbygdens Energi in Falköping (Slutarp)

2) Data description: The existing 13 wind turbines in the distribution system have a varying capacity factor between $20 \%$ and $28 \%$. From each of these wind turbines there is one year hourly measured active power data. Hourly measured active and reactive power data at the substation are also available for the same period. Adding the wind power data and the active power data from the substation, the load along with active power losses in the network is extracted. From this the minimum loading condition in the system is observed to be $0.5 \mathrm{M}$. Since most of these wind turbines operate at near unity power factor, the reactive power is assumed to come from the load. These time series load and wind power data are directly used in the optimization model. This also implies that the new wind farm is assumed to operate at unity power factor.

It should be noted that, with the given transformer size and the observed minimum loading condition, even without additional wind power, there is a probability of overloading the substation transformer. Hence, in the following analysis, WEC is used to increase the hosting capacity of the network. As the hosting capacity of the network is not limited by overvoltage problems, RPC has no significant role. 
B. Optimal hosting capacity of the distribution system with respect to the DSO

Tables I and II provide examples of network fee charged by Falbygdens energi ${ }^{2}$ [17]. The network fees depend on the rated capacity of wind power installed in the network, i.e. whether the installed capacity is below or above some regulator assigned value (currently 1.5 MW).

TABLE I: Network fees for rated power below 1.5 MW

\begin{tabular}{|l|l|l|}
\hline Type of connection & $\begin{array}{l}\text { Metage fee } \\
{[€ / \mathrm{yr}]}\end{array}$ & $\begin{array}{l}\text { Transmission benefit } \\
{[€ / \mathrm{MWh}]}\end{array}$ \\
\hline Connection to high voltage $(11 \mathrm{kV})$ & 899 & -2.38 \\
\hline Connection to low voltage $(0.4 \mathrm{kV})$ & 617 & -2.60 \\
\hline
\end{tabular}

TABLE II: Network fees for rated power above 1.5 MW connected to $11 \mathrm{kV}$ network

\begin{tabular}{|l|l|ll|ll|}
\hline $\begin{array}{l}\text { Subscription } \\
\text { fee }[€ / y r]\end{array}$ & $\begin{array}{l}\text { Peak power fee } \\
{[€ / M W / m o n t h]}\end{array}$ & $\begin{array}{l}\text { Distribution fee } \\
{[€ / M W h]}\end{array}$ & $\begin{array}{l}\text { Transmission benefit } \\
{[€ / M W h]}\end{array}$ & \\
\hline 3975 & 812 & 1.30 & -2.27 & \\
\hline
\end{tabular}

The different fees in Tables I and II are explained as follows:

- Metage fee is the fee paid by WFO to DSO for administration.

- Transmission benefit is the payment made by the DSO to the WFO to account for the benefits of distributed power production. On the other hand, Falbygdens energi gets the same level of reduction in payments made to the transmission system operator.

- Subscription fee is a yearly fee paid for subscription.

- Peak power fee is the monthly fee paid by WFO based on the maximum one hour average wind power injected.

- Distribution fee is the amount paid by WFO per MWh of electrical energy injected.

Assuming the installed capacity will be above $1.5 \mathrm{MW}$, the data in Table II are used for calculating the benefit of the DSO. Moreover, the costs of the DSO are the expense due to increase in network losses and the refund made to the WFO for curtailed energy. The monetary value of the cost of increase in power losses is taken to be the average spot market price for Sweden in 2011, $47.85 € / M W h$. For the curtailed energy the DSO pays the WFO the opportunity cost of the curtailed energy i.e. average spot market price plus the average cost of a green certificate. Besides the DSO will lose some portion of the revenue from network fee due to wind energy curtailment. On the other hand, the review of investment costs of different AMS implementation projects show that the cost varies between $100 \mathrm{k} €-850 \mathrm{k} €[27]-$ [32]. The costs vary depending on the number of points being monitored and controlled and the type of active management strategies being implemented and the type of communication media used between the different points. However, as pointed out in [33], the DSO may refund this cost by increasing the network fees. Of course, this will put additional cost on the

\footnotetext{
2 The data are original given in SEK. It is changed into $€$ using the all time average exchange rate, 9.2319 SEK $=1 €$ (as of Dec 4 2012), obtained from European central bank
}

WFO. Since some of these projects include the cost of research and development ( $\mathrm{R} \& \mathrm{D})$, the cost of AMS implementation is expected to decrease in the future. In the analyses carried out in this paper, this cost is assumed to be $200 \mathrm{k} €$. The WFO bears this cost instead of the DSO.

The AMS costs, which include the cost of curtailed energy and the implementation cost of AMSs, are compared against grid reinforcement which in this case is constructing a new substation. The cost of curtailed energy is taken as $\gamma=$ $75.77 € / \mathrm{MWh}$. This includes the loss in revenue from both green certificate and energy sell. The cost of new substation construction is roughly estimated to be $93000 € / \mathrm{MVA}^{3}$ [34]. Thus (13) can be rewritten as (18).

$$
75.77 \sum_{i} \sum_{t} P_{i, t}^{\mathrm{cur}}+200000 \leq 93000 \sum_{i} n_{i}
$$

Based on the cost and benefit data considered so far, the formula for calculating the coefficients of the objective function of the DSO is provided in the Appendix. The values of the coefficients are given in Table III for different capacity factor of the wind farm. It is assumed that the cash flows of the DSO due to the wind power does not change from year to year. Hence the coefficients are calculated to maximize the annual net benefit of the DSO. This provides the possibility to assess the net benefit of the DSO with different discount rates.

TABLE III: Coefficients of the objective function of the DSO for different capacity factor of the wind farm

\begin{tabular}{|r|r|r|r|r|}
\hline Capacity factor & $a_{i}[€ / \mathrm{MW}]$ & $b_{i}[€ / \mathrm{MW}]$ & $c[€ / \mathrm{MW}]$ & $d[€]$ \\
\hline $20 \%$ & 11426 & 85 & 48 & 3975 \\
\hline $24 \%$ & 11875 & 84 & 48 & 3975 \\
\hline $28 \%$ & 12367 & 83 & 48 & 3975 \\
\hline
\end{tabular}

The results of the analysis, as presented in Table IV, show that with a small percentage of curtailed energy a significant increase in hosting capacity can be achieved. With the existing transformer size and the minimum loading condition, it is possible to install only $10.5 \mathrm{MW}$ (= $10 \mathrm{MW}+0.5 \mathrm{MW}$ ) of wind power without overloading the transformer. But by allowing $1 \%$ WEC, in the case of wind power plant with $28 \%$ capacity factor, the hosting capacity is increased to 16.825 MW (= 12.225 MW + 4.6 MW). This corresponds to an increase of $60 \%$ in hosting capacity of the distribution system.

Table IV also shows the different cash flows of the DSO during the lifetime (assumed to be 20 years) of the project due to this additional wind power. These cash flows are calculated assuming a discount rate of 5\%. Compared to the cost of grid reinforcement needed, the cost of curtailed energy is less than one third. Moreover, curtailed energy is a more immediate solution for wind power integration than grid reinforcement.

On the other hand, the increase in network losses can be as important as curtailed energy in determining the hosting capacity of a given distribution system. So whenever large scale integration of wind power to a network is considered,

\footnotetext{
${ }^{3}$ Its average value is given in the reference as $112000 \$ / M V A$, but it is converted into $€$ here using the all time average exchange rate between $€$ and $\$$ i.e. 1.2103
} 
it is essential to study the resulting increase in the network losses.

However, Table IV does not show the hosting capacity to follow a specific trend with the capacity factor of the wind turbine. Though higher capacity factor generates increased revenue from network fee, it causes loss in revenue due to increase in curtailed energy and network losses. As a result, it is not straightforward to expect higher hosting capacity with increase in capacity factor as in the case of WFO, presented below.

TABLE IV: Optimal level of additional wind power in the system with respect to the DSO

\begin{tabular}{|l|r|r|r|}
\hline Capacity factor & $28 \%$ & $24 \%$ & $20 \%$ \\
\hline Additional capacity (MW) & 4.6 & 4.0 & 4.4 \\
\hline Curtailed Energy $(\%)$ & 0.9 & 1.3 & 1.6 \\
\hline Change in power losses (kW) & 27 & 18 & 19 \\
\hline Cost of curtailed energy $(€)$ & 100000 & 110000 & 120000 \\
\hline Cost of increased network losses $(€)$ & 140000 & 90000 & 90000 \\
\hline Revenue due to network fee $(€)$ & 760000 & 630000 & 660000 \\
\hline DSO's net benefit $(€)$ & 520000 & 430000 & 450000 \\
\hline WFO's net benefit ${ }^{4}(€)$ & 2634000 & 1086000 & 31000 \\
\hline Cost of grid reinforcement $(€)$ & 430000 & 370000 & 410000 \\
\hline
\end{tabular}

In summary the analysis shows that the DSO can use AMSs to increase the hosting capacity of the network thereby increasing the benefit obtained from wind power.

\section{Optimal hosting capacity of the distribution system with respect to the $W F O$}

Based on the discussion in Section II and the network fee data given in Table I, an estimate of the costs and benefits of a wind farm connected to the network of Falbygdens Energi are given in Table V.

TABLE V: An estimate of costs and benefits of a WFO

\begin{tabular}{|c|c|c|c|}
\hline \multirow{3}{*}{ Benefit } & \multicolumn{2}{|c|}{ Revenue from electricity sale $(€ / M W h)$} & 47.85 \\
\hline & \multicolumn{2}{|c|}{ Revenue from green certificate Sale $(€ / M W h)$} & 27.92 \\
\hline & \multicolumn{2}{|c|}{ Revenue from transmission benefit ( $€$ /MWh) } & 2.27 \\
\hline \multirow{6}{*}{ Costs } & \multicolumn{2}{|c|}{ Investment cost $(€ / \mathrm{MW})$} & 1225000 \\
\hline & \multicolumn{2}{|c|}{ O\&M costs $(€ / M W h)$} & 14.5 \\
\hline & \multicolumn{2}{|c|}{ Implementation cost of AMSs $(€)$} & 200000 \\
\hline & \multirow{3}{*}{ Network fee } & Distribution fee ( $€ / M W h)$ & 1.3 \\
\hline & & Peak power fee ( $€ / M W /$ month $)$ & 812 \\
\hline & & Subscription fee $(€ / y r)$ & 3975 \\
\hline
\end{tabular}

Using the cost and benefit data given in Table V, three cases are analyzed. The cases differ based on the capacity factor of the wind power and the discount rate of the investment. The coefficients of the objective function in (3) are calculated as in Table VI for the three cases. The cases are:

- Case 1: capacity factor $=28 \%$ and discount rate $=5 \%$.

- Case 2: capacity factor $=28 \%$ and discount rate $=7.5 \%$.

- Case 3: capacity factor $=24 \%$ and discount rate $=5 \%$.

The formulas for calculating these coefficients are given in the Appendix as (20).

Table VII presents the optimal hosting capacity, WEC level, and the net benefit of the WFO and the DSO for the three

\footnotetext{
${ }^{4}$ Calculated from the data given in Section IV-C
}

TABLE VI: The coefficients of the objective function of the WFO

\begin{tabular}{|r|r|r|r|}
\hline Case & $\alpha$ & $\beta$ & $\kappa$ \\
\hline 1 & 572280 & 729 & -249541 \\
\hline 2 & 245234 & 597 & -249541 \\
\hline 3 & 278853 & 721 & -249541 \\
\hline
\end{tabular}

cases. When calculating the net benefit of the DSO using (1) the formula for coefficient $b_{i}$ in (19) is modified as the DSO does not pay for curtailed energy. Similar modification is done to the coefficient $\beta_{i}$ in Subsection IV-B.

TABLE VII: Optimal wind power capacity with respect to WFO for different capacity factors and discount rates

\begin{tabular}{|l|r|r|r|}
\hline Case & 1 & 2 & 3 \\
\hline Additional capacity(MW) & 6.5 & 7.1 & 6.3 \\
\hline Curtailed Energy (\%) & 2.6 & 3.3 & 4.1 \\
\hline Change in power loss(kW) & 50 & 58 & 41 \\
\hline WFO's net benefit (€/lifetime) & 3190000 & 1160000 & 1570000 \\
\hline DSO's net benefit(€/lifetime) & 764000 & 798000 & 743000 \\
\hline
\end{tabular}

The different cash flows of the WFO are provided in Fig 2. These include revenues from electricity and green certificate sell, the expected investment cost, O\&M costs of the wind turbine, costs due to network fee, the cost of AMSs (including the cost of implementing the AMSs and curtailed energy), and the net benefit.

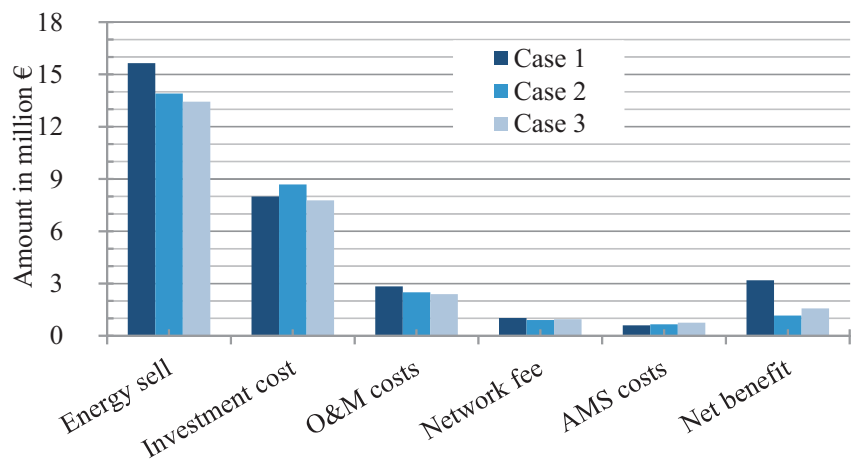

Fig. 2: Expected cash flows of the WFO for each scenario shown in Table VII

Compared to the results in Table IV, the additional curtailment in wind power, e.g. $(2.6 \%-0.9 \%) / 0.9 \%=1.9$, does not result in a comparable boost in hosting capacity of the network, e.g. $(6.5-4.6) / 4.6=0.4$. But still a significant increase in hosting capacity, $78 \%(=(12.225+6.5-10.5) / 10.5)$, is achieved with relatively small curtailed energy, 2.6\%. Moreover the cost of AMS, as shown in Fig 2, is very low compared to other costs of the WFO.

Table VII shows also that the hosting capacity decrease with the decrease in capacity factor of the wind turbine. This is reasonable as less capacity factor implies less revenue for the WFO. Hence the WFO has less motivation to install more wind power when part of the electricity production is to be curtailed. 
Table VII shows also that when the discount rate is increased i.e. from Case 1 to to Case 2, more wind power is installed. This is because the hosting capacity in the analysis is limited due to the constraint in (18) i.e. as further increase in hosting capacity using WEC is found to be less profitable than investing on new substation. Grid reinforcement, in our analysis, is composed of upfront costs only, hence does not depend on discount rate. On the other hand, with higher discount rate the net present value of the cost of curtailed energy would be less. Hence with higher discount rate, higher wind power capacity can be installed by curtailing more wind energy.

Fig. 3 presents more clearly the idea discussed in paragraphs above. The analysis is done for wind power having a capacity factor of $28 \%$.

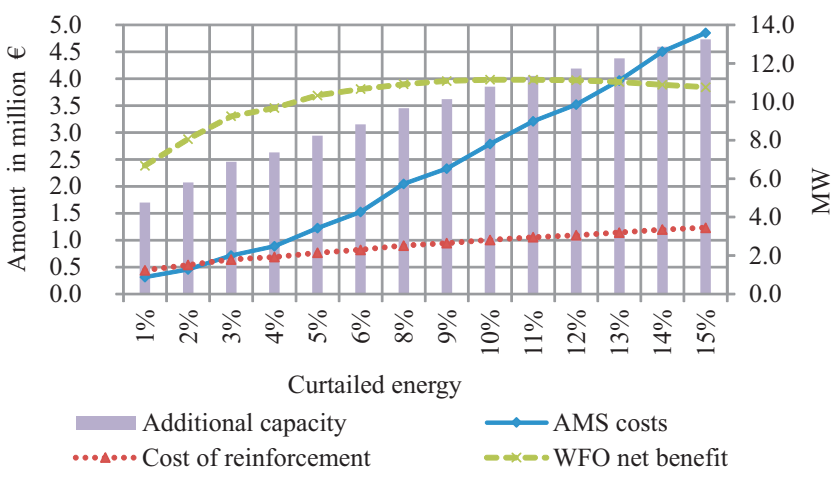

Fig. 3: Comparing the investment options of the WFO

The figure shows that the hosting capacity of the distribution system can be increased indefinitely using curtailment. But the net benefit of the WFO increases only until the curtailed energy reaches $10 \%$. Even curtailing this much energy to increase the hosting capacity is unreasonable as the alternative option, i.e. grid reinforcement, can generate more profit. In fact, as can be seen from Fig. 3, WEC is attractive only up to $2.6 \%$ curtailed energy.

On the other hand, Fig. 4 shows the costs and benefits of the DSO when the WFO bears the cost of curtailed energy. Despite significant loss in revenue due to increased power losses, the DSO continues to generate more revenue as the capacity of wind power in the system is increased.

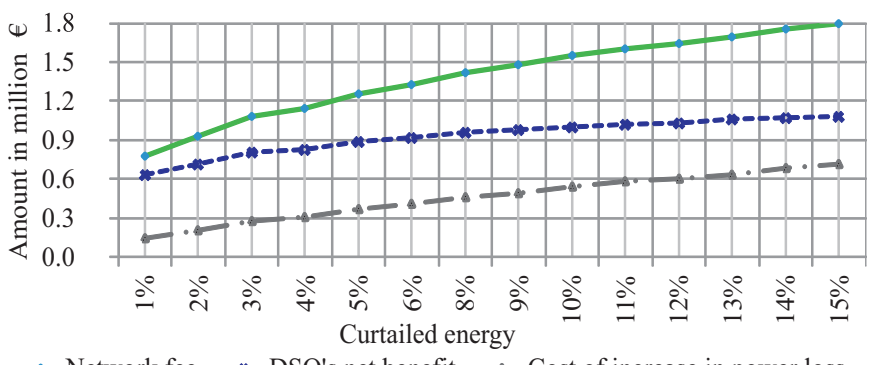

$\longrightarrow$ Network fee $-*$ - DSO's net benefit $\rightarrow$ Cost of increase in power loss

Fig. 4: Costs and benefits of the DSO

\section{Sensitivity analysis}

In the previous analyses, some fixed monetary values are assumed for a number of cost types which are more likely to vary from project to project and from time to time. Here a sensitivity analysis is provided to take this variability in the different costs into account. The sensitivity analysis is done on optimal hosting capacity of the network with respect to the WFO, i.e. based on the model considered in Subsection IV-C.

Several factors affect the net present value of the income of the WFO per MW of wind power installed. These factors include the capacity factor of the wind turbine, the discount rate, the investment cost of the wind turbine per MW, the O\&M cost of the wind turbine, and the revenue from energy sell (this includes the price of electricity and green certificate). The availability of the wind farm can be included in the capacity factor of the wind farm. The variability of each factor affects the optimal capacity and the net benefit of the WFO differently. This has been seen for discount rate and capacity factor of the wind farm in the Section IV-C. In this section the average revenue of electricity sell is varied from 57 to 72 while keeping the remaining factors constant: capital cost $=1150$ $000 € / \mathrm{MW}$, O\&M costs $=12 € / \mathrm{MWh}$, discount rate $=5 \%$, and capacity factor $=28 \%$. This has resulted in net income per MW varying from $200 \mathrm{k} €$ to $700 \mathrm{k} €$. In contrast, the net income considered in Section IV-C is $656554 € / \mathrm{MW}$.

Similarly, varying levels of monetary values are considered for the cost of AMS implementation and the cost of grid reinforcement. Using the review of project costs provided above as basis, we have varied the cost of AMS implementation from $100 \mathrm{k} €$ to $400 \mathrm{k} €$. For the grid reinforcement, we have varied the cost from $75 \mathrm{k} €$ to $150 \mathrm{k} € / \mathrm{MW}$ using the data in [35] as basis.

Fig. 5a shows that with increased net income per MW more wind power can be installed until the constraint in (18) takes effect. For example, in Fig. 5a, when the net income per MW is above $400 \mathrm{k} €$ the hosting capacity decreases because the cost of curtailed energy increases. The cost of curtailed energy increases as there is an increase in price of electricity per MWh. Thus, (18) takes effect at a lower curtailment level and hence at a lower capacity. On the other hand, it can generally be said that with net income per MW below $200 \mathrm{k} €$ it is not promising to invest on wind power even if the cost of AMS strategies very low, as the cost of network fee is about 160 $\mathrm{k} € / \mathrm{MW}$.

Moreover, Fig. 5b shows that the optimal wind power hosting capacity of the network with respect to the WFO increases with decrease in cost of AMS implementation if the remaining factors are constant. When the cost of AMS implementation increases, at some point, AMSs are no longer a better solution than the grid reinforcement. However, it is interesting to notice that the cost at which AMS ceases to be attractive is significantly higher than the cost of grid reinforcement per MW of increase in hosting capacity.

Furthermore, Fig. 5c shows that when the cost of reinforcements falls to $50 \mathrm{k} € / \mathrm{MW}$ it will not be attractive to invest on AMS. With the increase in reinforcement cost, the AMS option becomes more attractive to install more wind power.

In summary WEC can be used to increase the hosting capacity of a given network. The optimal level of hosting capacity and curtailed energy depends on the capacity factor of the wind power plant and the discount rate. With respect to the 


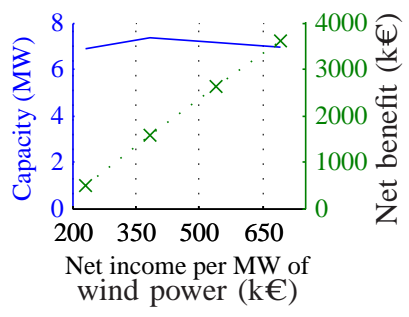

(a)

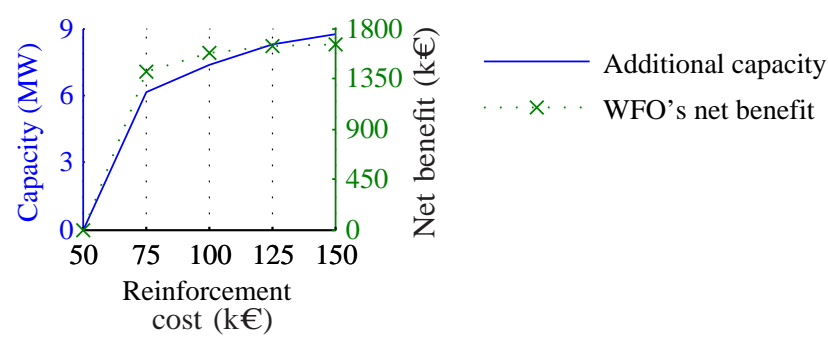

(c)

Fig. 5: The optimal capacity of the network for different levels of (a) net income per MW of wind power installed(AMS implementation $\cos \mathrm{t}=200 \mathrm{k} €$, Reinforcement $\cos \mathrm{t}=100 \mathrm{k} €$ ) (b) AMS implementation costs (Reinforcement cost $=100$ $\mathrm{k} €$, Net income per $\mathrm{MW}=385 \mathrm{k} €$ ), and (c) expected grid reinforcement costs (AMS implementation cost $=200 \mathrm{k} €$, Net income per $\mathrm{MW}=385 \mathrm{k} €$ )

WFO, higher capacity factor implies higher hosting capacity. But it is also affected by the discount rate, the cost of curtailed energy, and the cost of the alternative investment option i.e. grid reinforcement. Moreover in most cases analyzed in Fig. 5 the optimal hosting capacity is limited by the constraint in (18). This means the WFO can install more wind power without a decrease in the net benefit. However, if the WFO plans to install more wind power it would be better to invest on grid reinforcement and gain higher net benefit than that can be obtained by using AMSs.

\section{CONCLUSION}

A model based on cost benefit analysis is proposed for determining the optimal wind power hosting capacity of a distribution system using AMSs. The model also ensures the profitability of using AMSs compared to grid reinforcement. The case study in this paper specifically focuses on optimizing the hosting capacity using WEC. In this regard, it is seen that the optimal hosting capacity of a given network is dependent on who covers the cost of curtailed energy: the DSO or the WFO. In either case, the hosting capacity is increased considerably.

In the case of the DSO, the hosting capacity of the network is increased by as much as $60 \%$ by allowing a mere $1 \%$ WEC. Moreover, for the DSO, the increase in power losses can have as much effect on the hosting capacity as the WEC. The level of this effect depends on the resistivity of the grid from the point of connection onwards.
For the WFO, the increase in hosting capacity depends on the capacity factor of the wind turbines and the discount rate. In our analysis, the hosting capacity is increased by as much as $78 \%$ with $2.6 \%$ WEC. Unlike the case of DSO, here the hosting capacity is limited as the alternative option, i.e. grid reinforcement, becomes more attractive than curtailment if the WFO wants to install more. Hence when determining the optimal level of wind power curtailment, one should not only focus on the profitability of the WEC but also conduct a comparison with an alternative option, such as grid reinforcement.

Moreover, under the assumptions and data used in this paper, the investigated distribution system has a higher installed wind capacity if the WFO pays the curtailment instead of the DSO.

It should be noted that many of the parameters (cost and benefits) considered in this paper may change from one regulatory period to the other. That is, the calculated optimal hosting capacity as well as the net benefit obtained by each actor can vary. Hence the concerned actor may need to make additional sensitivity analysis.

On the other hand, though a small scale distribution system is used here, the model is also tested using a 69-buss system with wind farms at multiple locations. The result has shown that the model can also be applied to larger systems. Appropriate scaling of the constituent equations and variables ensures faster convergence.

\section{APPENDIX}

A. calculating the coefficients of the objective function

1) DSO objective function:

$$
\begin{aligned}
& a_{i}=f^{\mathrm{mp}} n^{\mathrm{mon}} \rho^{\mathrm{pf}}+f_{i}^{\mathrm{cf}} \rho^{\mathrm{df}} \\
& b_{i}=\frac{h^{\mathrm{yr}}}{T}\left(\rho^{\mathrm{df}}+C^{\mathrm{e}}+C^{\mathrm{gc}}\right) \\
& c=C^{\mathrm{e}} h^{\mathrm{yr}} \\
& d=\rho^{\mathrm{sf}}
\end{aligned}
$$

\section{2) WFO objective function:}

$\alpha_{i}=\left(\left(C^{\mathrm{e}}+C^{\mathrm{gc}}+\rho^{\mathrm{tb}}-C^{\mathrm{v}}-\rho^{\mathrm{df}}\right) f_{i}^{\mathrm{cf}}-f^{\mathrm{mp}} n^{\mathrm{mon}} \rho^{\mathrm{pf}}\right) \times f^{\mathrm{npw}}$

$-C^{\mathrm{c}}$

$\beta_{i}=\frac{h^{\mathrm{yr}} f^{\mathrm{npw}}}{T}\left(C^{\mathrm{e}}+C^{\mathrm{gc}}+\rho^{\mathrm{tb}}-C^{\mathrm{v}}-\rho^{\mathrm{df}}\right)$

$k=-\rho^{\mathrm{sf}} \times f^{\mathrm{npw}}-C^{\mathrm{am}}$

$f^{\text {npw }}$ is the net present worth factor and is given by [36]

$$
f^{\mathrm{npw}}=\frac{(1+r)^{\mathrm{Tp}}-1}{r(1+r)^{\mathrm{Tp}}}
$$

\section{ACKNOWLEDGMENT}

The authors would like to acknowledge Lars Ohlsson from Falbygdens Energi for providing network and measurement data. 


\section{REFERENCES}

[1] REN21, "Renewables 2013 global status report," Jun 2012.

[2] S. Krohn, P.-E. Morthorst, and S. Awerbuch, "The economics of wind energy," European Wind Energy Association (EWEA), Brussels, Tech. Rep., Mar. 2009.

[3] S. Liew and G. Strbac, "Maximising penetration of wind generation in existing distribution networks," Generation, Transmission and Distribution, IEE Proceedings-, vol. 149, no. 3, pp. 256 -262, May 2002.

[4] B. Kuri, M. Redfem, and F. Li, "Optimisation of rating and positioning of dispersed generation with minimum network disruption," in Power Engineering Society General Meeting, 2004. IEEE, June 2004, pp. 2074 -2078 Vol.2.

[5] G. Celli, E. Ghiani, S. Mocci, and F. Pilo, "A multiobjective evolutionary algorithm for the sizing and siting of distributed generation," Power Systems, IEEE Transactions on, vol. 20, no. 2, pp. 750 - 757, May 2005.

[6] G. Harrison, A. Piccolo, P. Siano, and A. Wallace, "Distributed generation capacity evaluation using combined genetic algorithm and opf," International Journal of Emerging Electric Power Systems, vol. 8, pp. 750 - 757, 2007.

[7] M. Mardaneh and G. Gharehpetian, "Siting and sizing of dg units using ga and opf based technique," in TENCON 2004. 2004 IEEE Region 10 Conference, vol. C, Nov. 2004, pp. 331 - 334 Vol. 3.

[8] G. Harrison, A. Piccolo, P. Siano, and A. Wallace, "Exploring the tradeoffs between incentives for distributed generation developers and DNOs," IEEE Transactions on Power Systems, vol. 22, no. 2, pp. 821 -828 , May 2007.

[9] P. Siano, P. Chen, Z. Chen, and A. Piccolo, "Evaluating maximum wind energy exploitation in active distribution networks," Generation, Transmission Distribution, IET, vol. 4, no. 5, pp. 598 -608, May 2010.

[10] J. Mutale, "Benefits of active management of distribution networks with distributed generation," in Power Systems Conference and Exposition, 2006. PSCE '06. 2006 IEEE PES, Nov. 2006, pp. $601-606$.

[11] A. Shafiu, T. Bopp, I. Chilvers, and G. Strbac, "Active management and protection of distribution networks with distributed generation," in IEEE Power Engineering Society General Meeting, 2004, Jun. 2004, pp. 1098 -1103 Vol.1.

[12] J. Zhang, H. Fan, W. Tang, M. Wang, H. Cheng, and L. Yao, "Planning for distributed wind generation under active management mode," International Journal of Electrical Power \& Energy Systems, vol. 47, pp. 140-146, May 2013.

[13] L. Ochoa, C. Dent, and G. Harrison, "Maximisation of intermittent distributed generation in active networks," in SmartGrids for Distribution, 2008. IET-CIRED. CIRED Seminar, June 2008, pp. 1 -4.

[14] S. N. Salih, P. Chen, and O. Carlson, "Maximizing wind power integration in distribution system," in 10th International Workshop on Large-Scale Integration of Wind Power into Power Systems as well as on Transmission Networks for Offshore Wind Power Plants, October 2011.

[15] L. Ochoa, C. Dent, and G. Harrison, "Distribution network capacity assessment: Variable DG and active networks," IEEE Transactions on Power Systems, vol. 25, no. 1, pp. 87-95, 2010.

[16] R. Barth and C. Weber, "Distribution of the integration costs of wind power," IER-Stuttgart University, Deliverable D7.1, 2005.

[17] "Inmatningstariffer." [Online]. Available: http://feab.nu/ Inmatningstariffer-2011-2012.htm

[18] "Nätpriser - inmatning till lokalnät." [Online]. Available: http://www.fortum.com/countries/se/foretag/elnat/elnatspriser/ prislistor-lokalnat/pages/default.aspx

[19] "Statement of use of system charging." [Online]. Available: http://www. northernpowergrid.com/downloads/system.cfm

[20] M. I. Blanco, "The economics of wind energy," Renewable and Sustainable Energy Reviews, vol. 13, pp. 1372 - 1382, 2009.

[21] Svenska Kraftnät. [Online]. Available: https://elcertifikat.svk.se

[22] Nord Pool Spot. [Online]. Available: http://www.nordpoolspot.com

[23] A. Piccolo and P. Siano, "Evaluating the impact of network investment deferral on distributed generation expansion," IEEE Transactions on Power Systems, vol. 24, no. 3, pp. 1559-1567, 2009.

[24] H. Saadat, power system analysis. PSA publishings, 2010.

[25] S. Salih, P. Chen, and O. Carlson, "The effect of wind power integration on the frequency of tap changes of a substation transformer," IEEE Transactions on Power Systems, vol. 28, no. 4, pp. 4320-4327, 2013.

[26] A. Wächter and L. T. Biegler, "On the implementation of an interiorpoint filter line-search algorithm for large-scale nonlinear programming," Mathematical Programming, vol. 106, pp. 25-57, 2006.
[27] D. Pudjianto, D. M. Cao, S. Grenard, and G. Strbac, "Method for monetarisation of cost and benefits of DG options," Bericht im Rahmen des Europäischen Projektes DG Grid, Manchester/London, 2006.

[28] EDF Energy Networks Ltd, "IFI/RPZ report for EPN/LPN/SPN," Tech. Rep., 2010.

[29] SP Energy Networks, "Innovation funding incentive annual report," Tech. Rep., 2012.

[30] S. GRENARD, A. QUERIC, and O. CARRE, "Technical and economic assessment of centralised voltage control functions in presence of DG in the french MV network," in Proceedings of the 21st International Conference on Electricity Distribution, 2011.

[31] KEMA, "Smart grid strategic review: The orkney islands active network management scheme," Tech. Rep., Mar. 2012.

[32] Z. Hu and F. Li, "Cost-benefit analyses of active distribution network management, part II: investment reduction analysis," IEEE Transactions on Smart Grid, vol. 3, no. 3, pp. 1075-1081, 2012.

[33] J. Gordijn and H. Akkermans, "Business models for distributed generation in a liberalized market environment," Electric Power Systems Research, vol. 77, no. 9, pp. 1178-1188, Jul. 2007.

[34] P. Balducci, L. Schienbein, T. Nguyen, D. Brown, and E. Fatherlrahman, "An examination of the costs and critical characteristics of electric utility distribution system capacity enhancement projects," in Transmission and Distribution Conference and Exhibition, 2005/2006 IEEE PES, May 2006, pp. $78-86$

[35] G. Heffner, C. K. Woo, B. Horii, and D. Lloyd-Zannetti, "Variations in area- and time-specific marginal capacity costs of electricity distribution," IEEE Transactions on Power Systems, vol. 13, no. 2, pp. 560-567, 1998.

[36] H. L. Willis and W. G. Scott, Distributed Power Generation: Planning and Evaluation. Marcel Dekker, 2000.

Shemsedin Nursebo Salih was born on March 10, 1983 in Ethiopia. He studied his B.Sc. in electrical engineering at Arba Minch University, Ethiopia. He did his M.Sc. in power engineering at Chalmers university of Technology, Sweden, from where he graduated in 2010. Now he is doing his $\mathrm{PhD}$ degree at Chalmers University of technology. His research area is wind power integration in distribution system.

Peiyuan Chen (S'2007, M'2010) received his B.Eng. degree in Electrical Engineering from Zhejiang University, China, in 2004, M.Sc. degree in Electric Power Engineering from Chalmers University of Technology, Sweden, in 2006, and PhD degree in Stochastic Modelling and Analysis of Power System with Renewable Generation from Aalborg University, Denmark, in 2010. Currently, he is assistant professor at both Aalborg University and Chalmers University of Technology. His main research interests are optimal operation and planning of power system with integration of wind power.

Ola Carlson was born in Onsala, Sweden in 1955. He received the M.Sc. and Ph.D. degree in Electrical Engineering from Chalmers University of Technology, Gothenburg, Sweden in 1980 and 1988, respectively. He is currently a Professor in sustainable power production at the Department of Energy and Environment at Chalmers University of Technology. He had three years of industry experience in the areas of variable speed systems for wind turbines. His major interests are electrical systems for renewable energy and hybrid electric vehicles.

Lina Bertling (S'98,M'02,SM'08) was born in Huddinge, Sweden, in 1973. She has a Professor Chair in Sustainable Electric Power Systems at the Department of Energy and Environment at Chalmers University of Technology. She has been with Svenska Kraftnät, the Swedish Transmission System Operator during 2007-2009 and with the Royal Institute of Technology (KTH) during 1997-2009 where she finalized her Docent degree, Associate Professor, in 2008, and the Ph.D. in 2002, both in Electric Power Systems. Her research interests are in transmission and distribution systems including high voltage equipment and HVDC, and wind power systems with applications for reliability assessment and modeling, and maintenance planning. 